alteration of the functions of the spinal cord, and this patient led an active artisan's life for 15 years, having no signs of paraplegia. Another difficulty present is that no local pathological condition in the brain was found to account for the occurrence of the localised epilepsy.

It has been several times noted that some patients with syringomyelia bear operations and anæsthetics badly, and in a few reported cases, as in this one, an unexpected and rapid fatal result has occurred.

Wimpole-street, $\mathbf{W}$.

\section{FILARIASIS AND ITS CONSEQUENCES IN FIJI.}

By MORGAN I. FINUCANE, M.R.C.S. ENG., L.S.A., F.R.G.S.,

GOVERNMENT MEDICAL OFFICER AND PROVINCIAL INSPECTOR OF THE PROYIYCES OF TAILEVU AND RA.

THE prevalence of filariasis amongst natives and Europeans and its commonest result, elephantiasis of the scrotum, in the South Seas, and especially in Fiji, lead me to think that a description of the operation as usually performed in the Colonial Hospital at Suva, Fiji, would be of interest to your European readers. The illustrations ${ }^{1}$ which accompany these notes will show the formidable nature of the condition.

The patient being placed under deep anæsthesia-chloroform is invariably used in Fiji with good results-the scrotal tumour is well lifted up by an assistant and an Esmarch's elastic tourniquet is tightly pulled around the base or pedicle of the tumour; a couple of turns are necessary. The ends of the elastic tourniquet are brought obliquely growth. The index finger of the left hand is now introduced into this circular opening and the glans penis is felt. A curved, blunt-pointed bistoury is now passed along a grooved director or the finger above the glans penis, which is thas avoided, and the skin and subcataneous tissues freely divided for from one and a balf inckes to two inches. The glans penis is then seized and drawn forward and isolated and a No. 8 silver catheter is passed, an assistant holding the penis well dragged forward on the catheter and raised towards the abdomen. The penis is then dissected out, the surgeon removing freely all elephantoid prepuce and in clearing it the catheter acts as a safe guide in avoiding the urethra, a wound of which might readily be made in its absence. When this is completed the penis with catheter in situ is held well up by an assistant over the abdomen. A long incision is then made from the external abdominal ring over the centre of each testicle almost to the lower margin of the scrotum. A largirh strong scalpel or small-sized amputating knife will be found best for dividing the large, thick, and indurated elephantoid scrotum which is so commonly found in chronic cases coming for operation. A free cutting incision must be made the whole length of the first skin incision. Numerous transverse fibrous bands will be met with and require division, and the knife, if not firmly beld, will be apt to slip, as there is a continuous exudation of varying quantities of serous and blood-stained fluid. The tunica vaginalis being readily recognised is freed at its lower end and disseeted out with its contents by a process of tearing and cutting. Some care is required in dissecting out the cord and removing masses of elephantoid gelatinous tissue adhering to it; a few large veins also sometimes require ligature. It is very rare to find cases of elephantiasis requiring operation in which there is not a hydrocele. In fact, as a rule the hydrocele is very

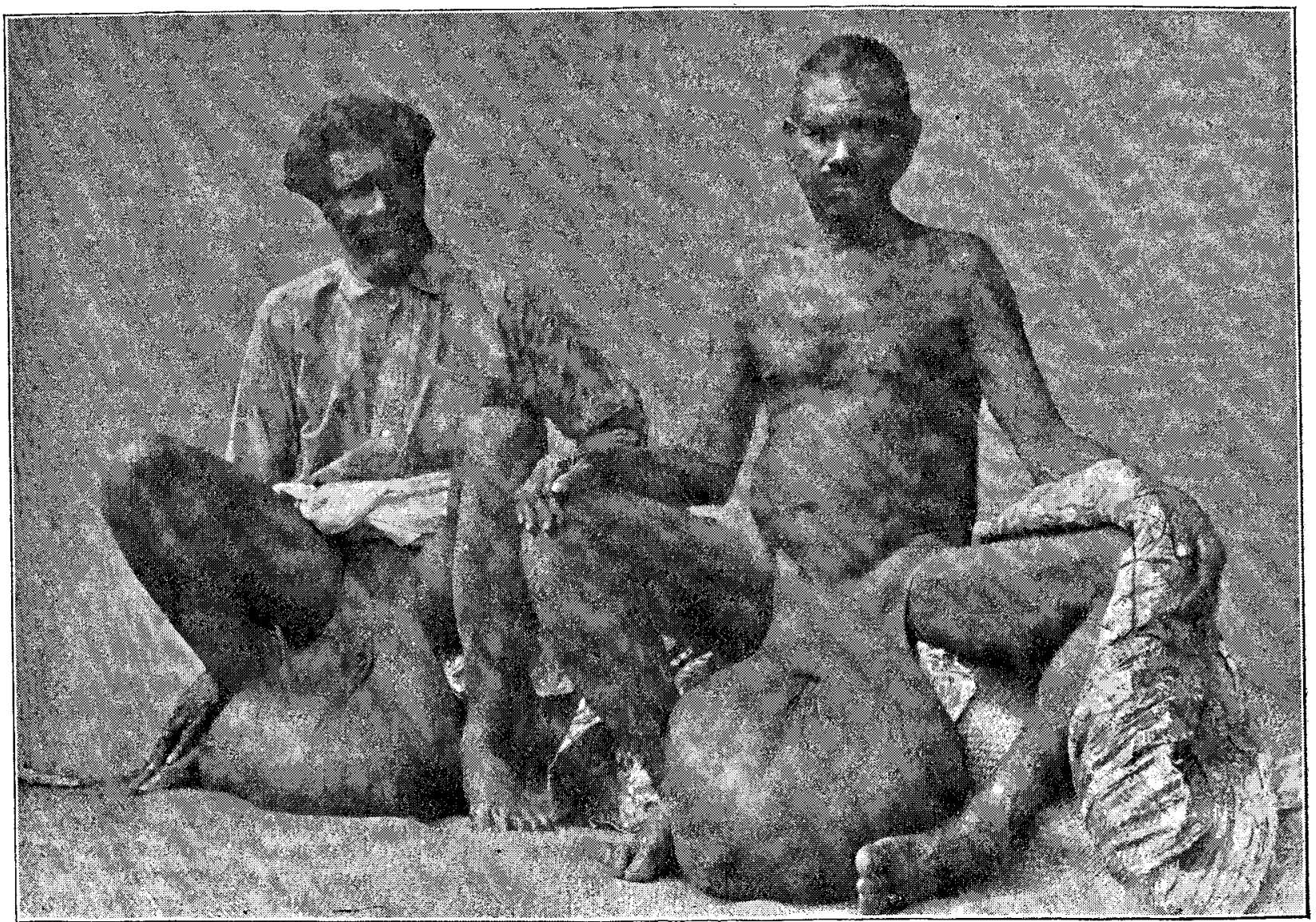

Two typical cases of elephantiasis of the scrotum.

across Poupart's ligament above the crest of the pelvis to unite behind or at the side, and undue pressure is prevented by padding near the various bony points with cotton-wool. There is now before the operator a huge scrotal mass, in the upper and central portion of which there is a circular depression, the preputial orifice, at the bottom of which is the penis deeply buried in the surrounding elephantoid

I We have selected for reproduction one from the many interesting photographs sent to us by Mr. Finucane.-ED. L. large, accounting in a good many cases for the size of the umour.

It is now necessary, having dissected ont both testes and cord right up to the external abdominal ring, to evacuate the contents of the hydrocele with a trocar and canula, afterwards cutting away the thickened elephantoid tunica vaginalis, leaving only the testis and cord on each side. Both testes being held ap over the abdominal wall, the operator proceeds to fix the base of the tumour by skewers introduced as high up as possible, so as to avoid all 
elephantoid tissues, but immediately below the tourniquet. $\mathrm{He}$ passes the point of the skewer transversely across the perineum, guided by his left index finger. He carefully avoids the urethra which might easily be transfixed if care were not taken and he makes the point emerge as high as possible on the opposite side at a point corresponding to the entrance wound. A strong cork is then put on the point of the skewer to avoid injuring the left leg. The second skewer is introduced on the left side and as near the posterior part of the perineum as possible; it is similarly dealt with and secured on the right side by another cork. These skewers act as a hold on the perineal skin after division of the tumour and prevent retraction of the mass and play an important part in preventing hæmorrhage ; in fact, the removal of the largest elephantiasis can be carried out in an almost bloodless way if this course is pursued. The surgeon then divides the tumour about a line's length below the lower skewer, cutting freely through the growth in front and working circularly around the tumour, dividing last the retracting perineum. Were it not for the skewers on removal of the growth the retracting perineum would slip through the Esmarch's tourniquet and considerable hæmorrhage delay the completion of the operation. The vessels are now picked up one by one and tied at once, in largish tumours as many as 20 or 30 being met with requiring a ligature. The skewers are now removed, the tourniquet is loosened, and general oozing is dealt with, of which sometimes there is a considerable quantity from enlarged veins about the testes and cords. The edges of what is really part of the perineum and inner sides of the thigh are now brought together and the paucity of skin is sometimes alarming, leading the operator to fear whether he may be able to accommodate the now swollen testes. The skin, however, here is readily adaptable and a good scrotu in can always be fashioned.

In native Fijians it is rarely necessary to drain the new scrotum; wire and silk sutures are put in the whole length and as much of the denuded penis covered up by surrounding healthy skin as is possible. Healing of the scrotum by first intention is the rule, but owing to the necessity of granulation of the penis the recovery in Fiji after this operation is rarely completed under three months. In operating on an elephantiasis of the scrotum the possible presence of a hernia complicating matters must be carefully borne in mind. It is not a common experience in $F_{1 j} i$, but nevertheless does occasionally occur. Fijians as a rule do not come for operation until the growth is large and it is unusual for any to be seen in the Colonial Hospital under $10 \mathrm{lb}$. in weight, and some cases have been enormous, one recorded by Sir William McGregor weighing $100 \mathrm{lb}$.

As to the clinical history of filariasis and its results in Fiji, it is prevalent all over the Fijian group and attacks every race, being, of course, more common among native Fijians It is to be seen in its most virulent forms in lowlying, swampy districts, such as on the Rewa Delta. is almost impossible to find an adult person free from elephantoid enlargement of some portion of the body in the coast towns of $R_{\lambda}$ province, and it is extremely common in the mountain villages of Colo in Viti Levu. Needless to say, bush, town swamps, stagnant water, and mosquitoes abound in all Fijian villages

Cutaneous and deep lymphatic varix and orchitis, lymph scrotum and elephantiasis, are all to be met with in varying stages of the disease. Elephantoid enlargement of the leg, the arm, and the breast is very common amongst Fijian women, and the disease is occasionally met with attacking the vulva. Every growing Fijian child suffers periodically from "wagaga," which is simply an attack of lymphangitis, generally occurring in an extremity, an arm or a leg, but most frequently in the male it affects the testicle or cord, suggesting a commencing "evididymitis." With this "wagaga" there is fever, headache, and general malaise. It is not common to be able to define or see the inflamed lymphatic cord in the native, though amongst Europeans and half-castes it is nearly always noticeable. The commonest result in these cases is the formation of an abscess which terminates the attack, and the patient returns to his ordinary heaith to await another outburst of filariasis, most Fijians being liable to four or five such attacks annually. It would be rare to find a Fijian who did not bear on his body the many previous scars of former filarial abscesses, either opened by a surgeon's knife or by the natural process of suppuration, or more commonly as the result of his own incision by a sharpened bamboo. The character of the abscess is small and circular, and on excision there exudes thick, creamy pus, followed by a small clot or flow of blood, suggestive of embolic plugging of an area of capillary or lymphatic tissue. Other cases I have seen where the lymphangitis stopped short of suppuration, producing diffuse matting together of the tissues of the abdominal wall, and where the patient passed rapidly into a septic condition and died. In the earlier stages, betore any local symptoms show themselves, these cases are extremely puzzling and much resemble the remittent form of malaria, a disease happily almost unknown in Fiji.

The chronic variety of filariasis producing elephantiasis is next to abscess the commonest form in Fiji and for it the operation described above has to be frequently performed. Chyluria is rare in Fiji and the filarial attacks more com. monly result in the other conditions already described.

Quinine is given with good effect in acute filarial attacks and at the same time local remedies are employed.

\section{A CASE OF MOLLITIES OSSIUM WITH SPONTANEOUS FRACTURE THROUGH THE GREAT TROCHANTER OF THE LEFT FEMUR.}

\section{BY J. HOGGAN EWART, M.D. EDIN.}

\section{THE following case presents many points of interest.}

The patient was a widow, aged 65 years. Her mother had died from cancer at the age of 50 years. There was no history of bone troubles in the family. The patient had always had very comfortable surroundings. She had had no severe illnesses, but had suffered from menorrhagia for several years and a polypus was removed from the uterus 14 years ago. She had had 10 children, but with the exception of the first confinement, which was tedious, there was nothing to note. She had always led a very active life. 14 years ago she first noticed that her left ankle was thicker than the right, and she showed it to a medical man who told her not to worry, and she left it alone for two years, when she showed it to Dr. Donglas of Newbury, who has kindly sent me a note to the effect that she consulted him for rbeumatism and he discovered a yielding of the tibiæ and warned her that if she persisted in walking she would find herself with broken bones. She did not trouble berself much, but gradually she noticed that the right shin-bone was becoming very bent like the left. How ever, she managed to get about with the help of a stick. On March 1st last she suddenly felt a pain in the upper part of the left thigh and associated it with a small lipoma which had existed for years. The pain increased and she saw a medical man who told her that it was rheumatism and ordered hot fomentations and massage, but on March 15th while walking with a stick and leaning on her daughter's arm they both heard a crack and the patient subsided on to the ground. I saw her shortly after the accident and diagnosing an extra-capsular fracture of the left femur put the limb up on a Liston's long splint with weight extension and gave a very guarded prognosis. I noted great deformity affecting the left side of the pelvis, both femurs, and both tibiæ; all the other bones, however, were normal. The urine showed a marked increase in phosphates. About three weeks af ter the accident a skiagram was taken (see Fig.), which showed the fracture which had taken place through the great trochanter of the left femur. The splint was removed at the fifth week and sand bags were substituted.

At the ninth week another skiagram was taken which showed that the fracture had united with osseous union, a large amount of callus having been thrown out. This condition could also be verified by manipulation. A third skiagram was taken which showed the deformity affecting the left tibia (see figure). This skiagram is interesting in that it shows the effect of the disease on the texture of the bone. It will be seen that the tibia is more pervious to the $x$ rays in some parts than in others, so that it presents a mottled appearance. The fibula appears to be unaffected. (Note that the fibula should normally appear as a shadow over the length of the tibia, the skiagram having been taken from the inside.)

The patient is now (11 weeks (?) after the accident) able 